\title{
As narrativas jornalísticas curtas e a metodologia do haicai ${ }^{1}$
}

\author{
Monica Martinez ${ }^{2}$
}

1 Trabalho apresentado no $9^{\circ}$ Encontro Nacional da SBPJor (Associação Brasileira de Pesquisadores em Jornalismo), realizado na Escola de Comunicação da Universidade Federal do Rio de Janeiro (UFRJ), 03-05/11/2011.

2 Doutora em Ciências da Comunicação pela ECA-USP, com pós-doutorado em comunicação pela Universidade Metodista de São Paulo. Professora do Programa de Pós-Graduação da FIAMFAAM Centro Universitário. martinez.monica@uol.com.br 


\section{Resumo}

A instantaneidade propiciada pelo ambiente digital enfatiza, a cada dia, um dos limites clássicos do jornalismo: a questão dos espaços físicos reduzidos para a publicação de texto nos diferentes suportes impressos, radiofônicos, televisivos ou digitais. Nesse contexto, este artigo investiga experimentalmente a possibilidade de uso jornalístico de um tipo muito sintético de narrativa tradicional japonesa, o haicai, cujo método consiste na elaboração de uma mensagem com cerca de 17 sílabas. Este estudo empírico se baseia em oficina desenvolvida no primeiro semestre de 2011 com 127 alunos de graduação da habilitação de jornalismo, dos quais 51 responderam questionário sobre a experiência.

\section{Palavras-chave}

comunicação; jornalismo; narrativas jornalísticas curtas; haicai; Grêmio Haicai Ipê.

\section{Abstract}

The immediacy afforded by the digital environment emphasizes, every day, one of the classical limits of journalism: the issue of reduced physical space for the publication of text in print, radio, television or digital media. In this context, this paper experimentally investigates the possibility of using in journalism the haiku method, a very traditional and synthetic Japanese form of narrative which message is written with about 17 syllables. This empirical study is based on workshops developed in the first semester of 2011 with 127 undergraduate students of Journalism, of which 51 answered a questionnaire about the experience.

\section{Keywords}

communication; journalism; journalistic short narratives; haiku; Grêmio Haicai Ipê. 
Com a experiência do haicai, tivemos um limite de sílabas. No jornalismo teremos que trabalhar com certos limites, seja de sílabas, caracteres, linhas etc.

O haicai foi uma pequena amostra do que faremos bastante na profissão.

Brunielle Ferreira Silva

\section{A revolução digital}

Desde meados dos anos 1990, após a expansão da internet, houve uma transformação gradual, porém radical, na concepção, realização e compartilhamento das mensagens jornalísticas. Desde então, nada mais foi o mesmo no universo da comunicação.

Para fins didáticos, consideramos quatro fases principais no processo jornalístico:

- A primeira envolve a esfera da coleta de informações e consulta às fontes, feita por meio de acervos documentais e/ou entrevistas, entre outros.

- A segunda refere-se à redação da mensagem jornalística.

- A terceira etapa consiste na divulgação do material produzido.

- A quarta etapa está associada ao relacionamento posterior com as fontes, num contexto de responsabilidade social que emerge após a gradual redemocratização ocorrida na década de 1980, que visa a oferecer, em alguma medida, voz para diferentes grupos, com visões de mundo e interesses não raro divergentes.

A revolução digital teve impacto significativo no pensar e fazer jornalísticos. No quesito coleta de informações, por exemplo, os mecanismos de busca, sites e blogs institucionais ou pessoais abriram acesso às mais variadas fontes por meio do que viria a ser chamado de redes digitais e cooperativas sociais (CASTELLS, 2005, p. 444), permitindo uma pluralidade de vozes limitada 
somente pelo espaço, prazo e talento do jornalista como um apurador treinado para levantar informações relevantes ao interesse de seu público - aliás, cada vez mais segmentado e específico.

É sabido que a divulgação das mensagens também sofreu uma alteração impressionante, uma vez que a relação entre os participantes do processo comunicacional talvez represente a principal e mais evidente inovação propiciada pela rede digital. "Podemos distinguir três grandes categorias de dispositivos comunicacionais: um-todos, um-um e todos-todos" (LÉVY, 1999, p. 63). Se a primeira era clássica entre os meios de comunicação até então, a categoria todos-todos altera as próprias raízes do fazer jornalístico.

Este paper, contudo, tem o objetivo de refletir especificamente sobre as alterações notadas na esfera da redação jornalística. No mundo digital, os e-mails foram um dos primeiros instrumentos a antecipar a simplificação do formato e conteúdo das correspondências profissionais e pessoais. Nesse processo da abstração textual, talvez não haja caso mais exemplar que o da rede social Twitter. O protótipo, construído em duas semanas em março de 2006, foi lançado em agosto de 2006 pelos fundadores, os estadunidenses Biz Stone e Evan Williams. No rastro do sucesso, em maio de 2007 surgia oficialmente a Twitter Incorporated.

Quanto à natureza das mensagens, o projeto original previa a resposta em até 140 caracteres à pergunta "What are you doing?" (O que você está fazendo?), posteriormente alterada para a vigente "What's happening?" (O que está acontecendo?). Vários protagonistas do jornalismo brasileiro, como o apresentador e editor-chefe do Jornal Nacional, William Bonner, tornaram-se usuários. Como ele, milhões de internautas foram atraídos pela simplicidade e facilidade de acesso, uma vez que as mensagens podem ser enviadas por celular e SMS, além da própria rede. A instantaneidade dessa rede social garantiu-Ihe a primazia na divulgação de alguns fatos jornalísticos, como a morte do cantor estadunidense Michael Jackson em 25 de junho de 2009. 
Hoje o Twitter é considerado pequeno frente ao Facebook, a maior rede social do mundo, com 750 milhões de usuários em 2011 num mercado com pouco mais de dois bilhões de usuários (FERRARI, 2011). Mas também o Facebook tem restrições ao tamanho, uma vez que uma mensagem publicada no mural pode conter até 420 caracteres. Como se vê, no âmbito das redes sociais, o espaço continua a ser um desafio como sempre o foi para jornalistas de todos os meios, salvo, talvez, os que usam a plataforma do livro-reportagem como forma de expressão.

Nesse contexto, há outras áreas do conhecimento que apresentam contribuições quando o assunto é a produção de um texto conciso. Uma das mais interessantes é um segmento literário oriental muito específico: o da poesia tradicional japonesa.

\section{Breve história do haicai ${ }^{3}$}

O haicai (haiku em inglês ou 俳句 no ideograma japonês) é um poema conciso, formado por 17 sílabas fonéticas, distribuídas em três versos (5-7-5), sem rima nem título e com um termo relacionado a uma das quatro estações do ano (kigo).

Esse gênero poético popularizou-se durante o século XVII, na era Edo do Japão feudal e dos samurais, tendo como principal expoente Matsuo Bashô (16441694). Nascido numa família de guerreiros, Bashô teve educação esmerada, estudando com o filho do daímio que governava sua família e, posteriormente, sendo influenciado pelo zen-budismo. Segundo Paulo Franchetti (1996, p. 18), titular de Teoria Literária da Unicamp, ele eleva essa forma poética, até então dedicada ao gênero humorístico, ao nível espiritual de um "do, um caminho de vida, uma forma de ver e viver o mundo", como a ikebana, a tradicional arte

3 Nos textos consultados, a palavra haicai aparece com diferentes grafias, como haikai e hai-kai. Para facilitar a compreensão e a revisão, adotou-se o emprego do termo haicai, como faz no país o dicionário Aurélio e o tradicional Grêmio Ipê Haicai, de São Paulo. 
japonesa de arranjos florais. Disciplina faz parte dessa prática poética baseada em conceitos de sobriedade e tranquilidade (sabi), beleza e simplicidade (wabi), sutileza e leveza (karumi), notados no mais conhecido haicai do autor:

\author{
Velha lagoa - \\ Um sapo salta \\ O som da água. \\ Matsuo Bashô \\ (tradução de Paulo Leminski)
}

Num primeiro nível, o haicaísta é convidado a observar a natureza. Com o tempo, alguns praticantes conseguem imprimir às pequenas narrativas uma sofisticada reflexão sobre a realidade, evidenciando com sensibilidade o curto ciclo biológico humano (com sua roda de nascimento, crescimento, doenças, envelhecimento e, finalmente, morte), a esfera psíquica (tentações como luxúria e medo) e social (caso dos limites de aderência aos deveres sociais), ambientados no contexto da concepção budista, isto é, de impermanência e transitoriedade da vida ${ }^{4}$.

- Feliz Ano-Novo!

A voz de meu pai velhinho.

Cada vez mais débil.

Francisco Handa

4 Se fossemos atualizar o haicai para a contemporaneidade, provavelmente teríamos de tecê-lo a partir das inquietações que cercam o ser humano no presente, no contexto de sociedades capitalistas marcada pelos excessos do individualismo, do consumismo e da tecnologia (LIPOVETSKY; SERROY, 2011). 
No caminho do novo haicai aberto por Bashô seguem Yosa Buson (17151783), Kobayashi Issa (1763-1827) e Masaoka Shiki (1866-1902), nome artístico do poeta Masaoka Noboru.

No Brasil, a escola do haicai ligado à tradição japonesa inicia-se no século $X X$ :

Temos o registro de que Shuhei Uetsuka (1876-1935) - encarregado de conduzir os primeiros imigrantes pelo hoje histórico Kasato Maru, chegado ao porto de Santos em 18 de junho de 1908 - foi um bom poeta de haiku. Ele usava o haimei (nome literário de poeta de haiku) de Hyôkotsu (GOGA, 1988, p. 30-33).

Somente em meados da década de 1920 a prática começa a ser mais divulgada:

os homens que migravam na condição de trabalhadores contratados levavam vida apertadíssima, não tinham tempo "sequer de pensar em haiku". Era essa a realidade dos primeiros tempos dos imigrantes. Posteriormente, quando a vida do imigrante começa a apresentar alguma folga, mais precisamente em 1926, ingressa no núcleo colonial Aliança, Estado de São Paulo, Kan-ichiro Kimura, cujo nome haicaístico era Keiseki (1867-1938) e no ano seguinte Kenjiro Sato, de nome haicaístico Nenpuku (1898-1979). Eles lideraram o movimento de cultivo e de difusão do haiku tradicional, construindo os alicerces do atual "mundo haikuísta" da colônia japonesa (GOGA, 1988, p. 34).

Nempuku Sato era discípulo de Kyoshi Takahama (1874-1959), um dos seguidores de Masaoka Shiki (1867-1902), por sua vez um restaurador do haicai tradicional no Japão do século XIX, sendo considerado um dos quatro mais importantes da arte. 
Quando Nempuku emigrou para o Brasil, recebeu de seu mestre a missão de semear um país de haicais. O que ele fez, compondo em japonês e difundindo a arte no interior dos núcleos de imigrantes. Entre os seus discípulos estava Hidekazu Masuda Goga (1911-2008), que anos depois, em São Paulo, na companhia de Teiiti Suzuki - professor da Universidade de São Paulo -, manteria acesa a chama do haicai em japonês (FRANCHETTI, 2008, p. 267).

Goga dá início à difusão da vertente japonesa na comunidade nipobrasileira ${ }^{5}$ com a intenção de consolidar a produção do haicai clássico em língua portuguesa. Em 1987, funda em São Paulo o Grêmio Haicai Ipê, o primeiro de uma série de grupos dedicados ao estudo e prática haicaísticos.

Jacarandá em flor:

Saudade de minha mãe

que gostava de roxo.

H. Masuda Goga (GOGA; ODA, 1996, p. 178)

Em 1996, Goga lança Natureza - Berço do Haicai em parceria com sua sobrinha, a haicaísta nissei Teruko Oda. A obra - até hoje referência sobre termos associados às quatro estações do ano no país - contém produção de expoentes da área, como Teruko Oda - considerada a maior haicaísta contemporânea -, Edson Kenji Iura, Francisco Handa e Alberto Murata, entre outros.

5 Não é objeto deste trabalho a análise do haicai introduzido no país pela linhagem européia, cuja introdução é feita em 1919 por Afrânio Peixoto (1875-1947) (GOGA, 1988, p. 21). Essa divulgação teve grande impacto no movimento modernista de 1922, quando a forma concisa do haicai surge como ideal de coloquialidade, de registro direto da sensação e do sentimento, "tornando-se um modelo literário não-europeu para o projeto nacionalista brasileiro, que visava (...) romper os laços que nos amarram desde o nascimento à velha Europa, decadente e esgotada. (..) Sabemos hoje que o anônimo haicai japonês erguido como bandeira modernista nem era haicai, nem era japonês" (FRANCHETTI, 2008). Um segundo momento de interesse pelo haicai é despertado pelos poetas concretistas, desencadeado pela publicação de dois artigos por Haroldo de Campos no jornal O Estado de S. Paulo, respectivamente em 1958 e 1964, que privilegiam a forma do haicai "como um espaço para o virtuosismo técnico" (FRANCHETTI, 2008). Uma terceira onda seria desencadeada por conta de dois novos praticantes: o carioca Millôr Fernandes e o curitibano Paulo Leminski (1944-1989), que também não se vinculam ao haicai clássico. 


\title{
Kigo e métrica: técnica precisa por trás da aparente simplicidade
}

Fundador da The Haiku Society of America, Harold G. Henderson (18801974) aponta quatro regras clássicas do haicai em Haiku in English:

Consiste em 17 sílabas japonesas, divididas em três versos de 5, 7 e 5 sílabas; contém alguma referência à natureza; refere-se a um evento particular; apresenta tal evento como "acontecendo agora" e não no passado (CAQUI, 2009).

O Grêmio Haicai Ipê, o mais tradicional grupo brasileiro na vertente do haicai clássico, sugere observar-se a métrica, não recomendando ficar muito aquém nem além das 17 sílabas. Deve-se também evitar o estilo "prateleira" na composição, isto é, o ideal é que o primeiro e o segundo ou o segundo e o terceiro versos formem uma unidade:

\author{
Cuia de cabaça - \\ A libélula refletida \\ num resto de chuva.
}

Teruko Oda (ODA, 2010, p. 37)

O haicai clássico pede atenção especial à referência à natureza, o termo de estação conhecido como kigo (李語), poderoso recorte da realidade que "permite criar, muito economicamente, o mood característico que envolve e atribui significado a uma dada impressão sensória" (FRANCHETTI, 2008). Goga atribui emoções e etapas da vida às estações (primavera = alegria/juventude; verão $=$ mobilidade $/$ mocidade; outono $=$ melancolia $/$ maturidade; inverno $=$ tranquilidade/senilidade), explicando que a matéria-prima de um haicai é algo que desencadeie um sentimento em seu autor, seja ele uma emoção, imagem, sensação, lembrança, sonho ou desejo (GOGA; ODA, 1996, p. 250). 
Tomemos o kigo Carnaval, como exemplo. A mais popular festa brasileira é associada internacionalmente ao verão e à alegria típica dos trópicos. Desnecessário, portanto, gastar caracteres com estas palavras na narrativa, uma vez que elas estão implícitas no verbete - o que abre espaço para observações originais do autor. O "haicai fica muito mais rico na sugestão" (GOGA; UDA, p. 262).

\title{
Em meio à folia
}

Um olhar que é só ternura.

Ah... o Carnaval!

Alberto Murata (GOGA; ODA, 1996, p. 196)

Finalmente, a partir da classificação de Henderson, trata-se de um poema presentificado, que ocorre no aqui e no agora, embora seja natural que ele eventualmente desperte lembranças:

\author{
Brisa da manhã - \\ O cãozinho fecha os olhos \\ Por alguns instantes.
}

Edson Kenji Iura (IURA, 2011, p. 46)

A observação é local, contudo quando mais universal for a temática, maiores serão as chances de ela tocar leitores em qualquer lugar do mundo. 


\title{
O experimento
}

Em maio de 2011, foram realizadas oficinas com três turmas matutinas de primeiro-anistas da habilitação de Jornalismo do curso de Comunicação Social do campus Liberdade/SP da FIAMFAAM Centro Universitário. Essa oficina consistiu no ensino da metodologia do haicai e um exercício prático que solicitava aos alunos idealizarem um haicai sobre o tema Manhã de Outono, com o objetivo de relatar algum fato observado. Na semana seguinte, houve uma seleção coletiva dos haicais seguindo o modelo tradicional adotado no Grêmio Haicai Ipê, que consiste na leitura e votação sem identificação prévia do autor. Um exemplo dos resultados obtidos:

\author{
Um bocejo quente \\ combate o vento gélido \\ nesta manhã de outono.
}

Géssica Gomes Fernandes

Em seguida, criou-se um questionário online com a ferramenta do Google Doc Form, que foi enviado para 127 alunos. Desses, 51 responderam (40\%) até o deadline proposto (30 de maio de 2011), consentindo no uso das respostas para finalidade de pesquisa. O questionário consistia em 18 perguntas, contendo: termo de consentimento; seis questões relativas à identificação do perfil do estudante (nome, idade, dia de aula, e-mail, profissão e empresa), e quatro questões referentes à experiência, com respectivos espaços para comentários, mais um espaço final para comentários.

Para incentivar a aderência, a pesquisa foi planejada para ser respondida em poucos minutos, uma vez que a hipótese era a de que a maioria dos universitários trabalha para financiar os estudos, tendo pouco tempo livre disponível. Essa premissa não se comprovou, uma vez que há uma relação equilibrada entre estudantes que trabalham (52\%) e estudantes que se dedicam 
exclusivamente aos estudos (48\%) - dado provavelmente devido ao fato de a pesquisa ter sido aplicada em turmas matutinas.

Uma segunda hipótese, a de que os estudantes eram eminentemente jovens, foi comprovada. A maciça maioria (78\%) dos participantes tem até 21 anos. O restante se divide entre a faixa etária de 22 a 28 anos (14\%) e a de 29 a 35 anos (8\%). Esse dado, além do fato de serem alunos do primeiro semestre, talvez ajude a compreender o entusiasmo manifestado pela oficina de prática de haicai, que pode ser conferido nas cinco questões fechadas e aprofundado nas suas contrapartes abertas. Do total de participantes, $100 \%$ responderam afirmativamente às questões: 1) "Você acha que a observação é importante para o estudo e a prática da comunicação?", 2) A experiência com o haicai ajudou a prática da observação?".

A hipótese central da pesquisa era a de que a metodologia do haicai poderia estimular a observação isenta dos fatos e seu relato de forma concisa num contexto em que a prática das narrativas curtas é cada vez mais importante na área de comunicação e, em particular, no jornalismo. Essa premissa foi compreendida e endossada pelos participantes, como exemplifica a seguinte resposta: "Achei a experiência com o haicai muito interessante, pelo ponto da observação e pelo desafio de escrever com caracteres reduzidos" (Carlos Eduardo Gomes).

A contraparte quantitativa do estudo será analisada em cinco etapas:

1) Relação entre a comunicação e a observação.

2) Relação entre a prática do haicai e o estímulo à observação.

3) Importância das narrativas curtas no estudo e prática da comunicação.

4) Relação entre a prática do haicai e a produção e reflexão sobre mensagens jornalísticas curtas.

5) Contribuição do haicai na produção de um texto jornalístico objetivo. 


\section{Observação}

100\% dos participantes responderam afirmativamente à pergunta: "Você acha que a observação é importante para o estudo e a prática da comunicação?", opinião sintetizada na seguinte afirmação: "Como você descreverá o mundo sem observá-lo?" (Glauber de Lima Faria). Destacam-se os seguintes comentários, com ênfase na questão da criatividade:

1.1. Elemento essencial em comunicação: "A comunicação é baseada em observação de fatos, pessoas e lugares" (Erika Vilella Bezerra).

1.2. Elemento essencial em jornalismo: "A observação é muito importante para os jornalistas aprenderem a avaliar os fatos com mais exatidão" (Yago Leles).

1.3. Reconstrução da realidade: "A observação é o meio de representarmos mais fielmente as coisas a nossa volta. A partir da observação podemos recriar, da maneira mais realista possível, os cenários, as paisagens, as pessoas e até mesmo os sentimentos envolvidos em determinada situação" (Diane Neubüser).

1.4. Alteridade e compreensão do outro: "Com a observação penetramos no mundo de outra pessoa, outros seres vivos. Podemos até nos colocar no lugar deles e assim entender sobre suas vidas, o que querem, o que pensam, o que sonham" (Gisely Moreira da Silva).

1.5. Base para análise: "Através da observação, é possível analisar melhor os fatos que estão ocorrendo" (Natália Marcelino André). 
1.6. Credibilidade: "Os detalhes tornam uma notícia muito mais verdadeira" (Debora Ballerini Horta).

1.7. Criatividade: "É importante saber observar principalmente os detalhes, para que as produções não sejam comuns e superficiais" (Rafael Iglesias dos Santos); "Com a observação, a escrita fica com um diferencial" (Iris Santos de Santana); "Observação é um ótimo exercício para se perceber a realidade de outra forma e escrever textos originais" (Patricia Honório Boroski); "A observação é muito importante, pois a partir dela você consegue detalhes que muitas vezes passam despercebidos aos olhos dos demais. A prática da observação torna quem a faz mais criativo, perceptivo e até mais crítico, o que é essencial na carreira e prática da comunicação" (Paula Wrobel Monteiro).

\section{Relação entre haicai e observação}

$100 \%$ dos participantes responderam afirmativamente à pergunta: "A experiência com o haicai ajudou a prática da observação?". Destacam-se as seguintes:

2.1. Treino eficaz de observação: "Sim, hoje observo cada detalhe onde passo" (Poliana de Souza Santos).

2.2. Exercício com o idioma: "Sim, pois durante a realização do haicai tínhamos de prestar muita atenção nas sílabas, uma vez que deveríamos obedecer às regras solicitadas para a realização dele" (Gean Lucas Gonçalves Lima); "Ajudou, pois observando objetos, as formas e ações daquela manhã, foi possível passar a idéia de manhã de outono com mais clareza para o haicai" (Mayara Correa Braga). 
2.3. Estímulo à sensibilidade: "Com certeza, já que o método explora as palavras simples, o sentimento de cada um, mais que isso, aflora a sensibilidade e a métrica na linguagem por ser um exercício de concisão" (Natalia Danielle Kitajima).

2.4. Diálogo entre prosa e poesia: "A observação se deu num contexto mais objetivo, sem, contudo, deixar de ser poético. Ambos se auxiliaram. Um complementou o outro" (Eloá de Medeiros Araújo).

2.5. Reforço na capacidade analítica: "O fato de ter que refletir sobre coisas concretas, sem misturar o tal do sentimento, acaba privando parte da criatividade clichê, fazendo com que você analise mais o que está ao seu redor" (Luiz Henrique Sales).

2.6. Abertura para os sentidos e o novo: "A utilização dos cinco sentidos torna bem mais fácil desenvolver um haicai. E essa prática facilita uma maior percepção das coisas que se tem ao redor" (Viviane Ferreira); "Eu nunca tinha passado por uma experiência assim... Acabamos enxergando realmente as coisas" (Camila Corazza).

2.7. Compreensão profunda do fato observado: "Sim, foi necessário observar e inclusive vivenciar o tema 'manhã de outono' para o desenvolvimento de um haicai" (Igor Pequeno Sanchez); "O haicai ajudou a observar não apenas superficialmente como antes, mas a dar outro sentido e traçar analogias e até mesmo críticas a respeito da vida" (Guilherme Luiz Rodrigues Busto); "Percebo que os textos que costumo escrever por conta própria abordam temas como o materialismo e o perfeccionismo principalmente. Dessa maneira, admito que em palavras 
discorro muito sobre o que faz ou o que fazia parte do meu eu, para meu leitor mais do que sobre meu leitor. Com o haicai exercitei meu outro lado da escrita, observando somente o que está à minha volta, sem envolver-me" (Humberto Abdo de Lima); "Percebi que (...) coisas cotidianas, quando bem colocadas, podem render uma grande reflexão" (Jessica da Costa Gomes).

\section{Narrativas curtas e o estudo e a prática da comunicação}

Dos participantes, 98\% responderam afirmativamente à questão "Você acha que a prática das narrativas curtas é importante nos estudos e na prática da comunicação contemporânea", apontando as seguintes reflexões:

\subsection{Característica do novo ambiente comunicacional/social: "Com} os novos meios de comunicação, faz-se necessário obter informações de gêneros variados através de textos de menor porte" (Thais Bonate Santos). "A sociedade atual exige eficiência: rapidez + qualidade. A ferramenta mais importante é a concisão aliada ao conhecimento multifocal. As narrativas curtas são ótimas para o exercício da observação e da reprodução deste molde" (Júlia Maria de Oliveira Vianna).

3.2. Importância das narrativas curtas para o jornalismo: "É sim, pois as narrativas curtas nos ajudam a elaborar resumos, no caso da notícia" (Ananda Cavalcante Vasconcelos Cavalheiro).

3.3. Questão da concisão: "A prática de narrativas curtas é importante para o estudo e a prática da comunicação porque mostra como é necessário ser mais objetivo em um texto, que não é necessário falar muito para descrever uma situação" (Mariana Giordão Rosa); "Isso ajuda, 
para que possamos escrever um texto direto, conseguindo expressar o que gostaríamos, sem prolongar o texto" (Brunielle Ferreira Silva).

3.4. Relevância da objetividade: "Com a prática de narrativas curtas as pessoas aprendem a ir direto ao assunto, sem enrolar" (Alexandre Monteiro de Oliveira); "Sim, porque quanto menos você enrolar melhor será" (Marília Russiano Toledo Casari); "Uma experiência muito importante" (Leonardo Amorim Santana).

3.5. Questão do tempo: "Sim, pois cada vez a cidade fica mais rápida, fazendo com que as pessoas não tenham tempo para ler coisas grandes" (André Gabriel Guedes Ferreira).

3.6. Exercício de criatividade: "É importante para a prática da imaginação e o fortalecimento da criatividade, pois se expressar com poucas palavras e fazer o próximo entender o que você quer dizer é muito difícil e, com certeza, as narrativas curtas ajudam" (Felipe José Szpak); "Sim, ajuda a trabalhar a mente (Marcos Vinicius Alves Gementi); "Sim, e é bem difícil fazê-la" (Gabriella Valim Constantino).

\subsection{Visão crítica sobre a hegemonia das narrativas curtas em} jornalismo: "É importante sim, mas também não se podem deixar de lado as narrativas longas ou de um aprofundamento maior. O pequeno texto nos dá uma idéia num primeiro momento, fazendo com que pensemos sobre o assunto e, a partir daí, possamos desenvolver algo mais profundo. Nos dias de hoje, essa prática facilita o entendimento" (Ronaldo da Silva). 


\section{Relação entre haicai e prática de narrativas curtas em jornalismo}

Dos participantes, 96\% responderam afirmativamente à questão "Na sua opinião, a experiência com haicais ajudou na produção e na reflexão a respeito de mensagens jornalísticas curtas?", apontando os seguintes pontos:

\subsection{Familiarização com os limites da produção textual: "Esta} atividade que fizemos em sala foi muito produtiva para refletirmos sobre como escrevemos e também com o limite que devemos escrever, já que há casos em que temos limites" (Camila Valéria Caballero de La Fuente);

\subsection{Similaridade com alguns aspectos do texto jornalístico: "É} como fazer um lide, só que mais resumido" (Monalisa D' Julieth Gomes da Costa).

4.3. Aspecto lúdico do exercício: "Foi muito interessante e gostoso de se fazer e 'brincar'"' (Ana Carolina Santos Bacci).

4.4. Treino em narrativas curtas: "Sim, achei meio complexo de fazer, mas no final, deu tudo certo" (Mayara Vigato); "É muito mais complicado passar a ideia de forma direta e esclarecedora em poucas linhas, produzir um haicai é um exercício é tanto" (Thays Cristine Rodrigues Rufino); "Bom, se ajudou eu não sei, mais que me fez queimar a mufa, isso fez. Pois, para conseguir sintetizar as minhas idéias de um certo contexto em apenas 17 silabas, não foi fácil!" (Ricardo de Oliveira Catan).

4.5. Objetividade: "Mostrou que se falarmos somente o essencial conseguimos transmitir tudo que queremos passar para nosso leitor" 
(Tharcilla Cruvinel de Mello); "Aprendi a ser mais objetiva" (Divina Vieira dos Santos).

4.6. Expressividade: "Quando se produz um haicai tem que saber expressar todo um sentimento ou um objeto de forma a trabalhar sobre a sua forma de escrita, sabendo colocar o mais importante em evidência, e de um modo que os outros sintam e entendam aquilo" (Viviane Ferreira).

4.7. Facilidade de compreensão da mensagem: "Podemos apresentar rapidamente as mensagens de uma forma compacta, de entendimento mais fácil" (Eliana Maria de Oliveira).

\section{Relação entre haicai e objetividade em textos jornalísticos}

A quinta e última questão era a seguinte: "Para Teruko Oda, a maior haicaista brasileira contemporânea, a grande contribuição do haicai para os alunos de jornalismo é a experiência com o texto objetivo: 'Penso que a objetividade exigida pelo haicai leva o aluno a ver o acontecimento de um novo ângulo - mais descritivo, menos opinativo'. A partir da sua experiência com haicai, você concorda com a afirmação da haicaísta?". Dos participantes, 98\% endossam esta visão, contudo houve contribuições maduras sobre a tênue linha que separa a objetividade da subjetividade em jornalismo:

5.1. Objetividade: "O haicai de fato obriga uma objetividade com a qual eu não estava familiarizado" (Igor Pequeno Sanches).

5.2. Olhar apurado: "Sim, pois esse é o objetivo do haicai: desenvolver aquele olhar 'de ninja'" (Desiree Coriolano Alexandre Videira). 
5.3. Redução ao essencial: "Sim, pois mostra os fatos como eles são, sem muitos enfeites" (Gabriela Baleroni Sakamoto).

5.4. Destaque de alguns elementos da história: "Sim, os detalhes nos dão uma melhor imagem do acontecido" (Natalia Marques).

5.5. Visão subjetiva: "Na realidade achei que a mensagem que se passa para 'criar' um haicai é a de textos subjetivos, visões além do obvio, acima do que vemos, textos poéticos sem rima, mas com profundidade nas palavras. Exige sensibilidade, conhecimento, visão ampla e às vezes até lúdica" (Elaine Cristina Guimarães).

5.6. Objetividade não exclui opinião: "O haicai tem que ser objetivo, mas não deixa de conter a sua opinião, pois ela fica expressa do jeito com que você observa algo. No caso a nossa sala teve o mesmo tema, que foi desenvolvido e observado de maneiras diferente" (Erika Vilella Bezerra).

5.7. Interatividade textual: "Os textos geralmente demonstram cenas que precisam ser interpretadas pelos leitores" (Analice Ito).

\section{Considerações finais}

Esta pesquisa sugere que o haicai pode ser uma ferramenta promissora no ensino de narrativas, uma vez que $100 \%$ dos participantes responderam afirmativamente à primeira questão, apontando que o ato de observar é um elemento importante da comunicação e, em particular, do jornalismo, uma vez que permite a compreensão aprofundada dos protagonistas e da realidade, permitindo que o relato jornalístico seja crítico, fidedigno e criativo. 
Na segunda questão, $100 \%$ dos alunos estabeleceram uma relação concreta entre a prática do haicai e o treino da habilidade de observação. Na avaliação dos participantes, a oficina reforçou o uso do idioma e facilitou a transmissão da mensagem de forma clara. O exercício de concisão favoreceu uma visão mais sensível e compreensiva do mundo, uma vez que demanda intercâmbio entre os gêneros da prosa e da poesia para compor a mensagem. Ainda assim, os participantes notaram que a prática exige uma visão crítica, imparcial e, por vezes, vivencial do fato observado para seu correto relato. Mergulho que, na visão de alguns, leva à reflexão mais profunda sobre o acontecimento.

Do total, $96 \%$ dos participantes responderam afirmativamente à pergunta sobre a importância das narrativas curtas nos estudos e nas práticas comunicacionais contemporâneas (terceira questão), enfatizando o novo ambiente comunicacional surgido na era da internet e as implicações sociais dele advindas (maior qualidade/eficácia), bem como a alteração das percepções de tempo (mais corrido) e espaço (menores). Reportam, igualmente, que um texto conciso demanda imaginação e a criatividade, o que não é fácil de ser realizado. Contudo, também criticam a onipresença das narrativas curtas (que incentivam a brevidade a todo custo), o que não seria desejável nem ideal, uma vez que não permite o fomento de um jornalismo rico em sua variedade textual.

Os participantes relacionaram positivamente (96\%) o aprendizado do método do haicai à produção e à reflexão sobre mensagens jornalísticas curtas (quarta questão). Segundo eles, o treino ajudou na prática de alguns limites que cercam o jornalismo. Relataram também que encoraja o exercício textual numa base objetiva, porém lúdica em sua relação com a realidade e o idioma empregado. Por se tratar de alunos do primeiro semestre, houve evidentemente relatos de dificuldade na produção ("No momento ainda está complicado", Poliana de Souza Santos). Contudo, isso era esperado, uma vez que produzir mensagens curtas exige esforço até de profissionais da área. Ressaltam, porém, que o exercício ajuda a selecionar o aspecto essencial da mensagem, facilitando a compreensão por parte do leitor. 
Na quinta e última pergunta, sobre a relação entre o haicai e a objetividade em textos jornalísticos, 98\% dos participantes endossaram a visão da maior haicaísta brasileira contemporânea, Teruko Oda, de que a grande contribuição do haicai para os alunos de jornalismo é a experiência com o texto objetivo, que levaria o aluno a "ver o acontecimento de um novo ângulo - mais descritivo, menos opinativo". Os relatos indicam que a experiência ajudou na apuração do olhar e na concentração em detalhes essenciais da mensagem. Contudo, os participantes entendem que essa profundidade exige conhecimento e sensibilidade, elementos que são marcas do texto autoral. Assim, ainda que objetiva, a narrativa não deixa de conter a opinião do autor, "pois ela fica expressa do jeito com que você observa algo", justificando que, apesar do tema ser comum a todos, os resultados produzidos foram bastante diferentes. Um participante ressaltou que a mensagem haicaística só se completa ao ser interpretada pelo leitor - um efeito que é conhecido e muito buscado entre os praticantes desta modalidade poética.

À guisa de síntese das cinco perguntas, podemos dizer que os participantes entendem que a observação é vital na concepção e transmissão de mensagens curtas, em especial jornalísticas, uma vez que a visão objetiva é fundamental para o relato da realidade numa base crítica e criativa. Contudo, ressaltam que mesmo essas mensagens contêm uma marca autoral, uma vez que são feitas por um indivíduo que possui uma visão de mundo específica, situado num dado contexto espaço-temporal. Outro ponto sugestivo é o papel ativo do leitor na decodificação da mensagem, uma vez que a transmissão só se completa ao ser interpretada pelo receptor, que por sua vez também está imbuído de seu próprio arcabouço intelectual, afetivo e vivencial.

Para finalizar, ressalta-se que esta pesquisa empírica é experimental em jornalismo e que novos estudos, realizados em diferentes estágios da habilitação de jornalismo, bem como entre profissionais da área, seriam necessários para investigar de forma mais completa a usabilidade do método. Como aponta uma participante: "Certamente os haicais são tão difíceis de compreender plenamente 
quanto as mensagens jornalísticas. O estudo ajudou a aguçar o espírito crítico e a percepção - além de estimular a busca por mais uma fonte de cultura" (Júlia Maria de Oliveira Vianna).

De toda forma, os resultados sinalizam um diálogo promissor entre as narrativas tradicionais e contemporâneas, entre prosa e poesia, sugerindo que algumas respostas buscadas pela comunidade jornalística para enfrentar os desafios presentes e futuros da área podem estar nas raízes profundas da cultura humana. Nunca é demais lembrar que estudos como este somente são possíveis graças ao apoio dos jovens estudantes, aos quais se faz questão de registrar aqui um sincero agradecimento. 


\section{Referências}

CAQUI. O que é haicai. Disponível em: http://www.kakinet.com/caqui/nyumon.htm. Acesso em: 15.nov.2009.

CASTELLS, M. A sociedade em rede: a era da economia, sociedade e cultura. São Paulo: Paz e Terra, 2005.

FRANCHETTI, P. Haikai: Antologia e História. Campinas/SP: Editora da Unicamp, 1996. O Haicai no Brasil. Alea, Rio de Janeiro, v. 10, n. 2, dez. 2008. Disponível em: www.scielo.br/scielo.php?script=sci_arttext\&pid=S1517-106X2008000200007\&ln $\mathrm{g}=\mathrm{en} \& \mathrm{nrm}=$ iso. Acesso em: 15.nov.2009.

FERRARI, B. A babá de Mark Zuckenberg. Revista Época, São Paulo, p. 64-66, 18/07/2011. GOGA, H. M. O Haicai no Brasil. Tradução José Yamashiro. São Paulo: Oriento, 1988. GoGA, H. M.; ODA, T. Natureza - Berço do Haicai: Kigologia e antologia. São Paulo: Empresa Jornalística Diário Nippak, 1996.

IURA, E. K. In: ODA, T. (org.). Goga e haicai: um sonho brasileiro. São Paulo: Editora, 2011.

LÉVY, Pierre. Cibercultura. São Paulo: Editora 34, 1999.

LIPOVETSKY. G.; SERROY, J. A cultura mundo: resposta a uma sociedade desorientada. São Paulo: Companhia das Letras, 2011.

MARTINEZ, M. Tive uma ideia! O que é criatividade e como desenvolvê-la. São Paulo: Paulinas, 2010. Jornada do herói: estrutura narrativa mítica na construção de histórias de vida em jornalismo. São Paulo: Annablume/Fapesp, 2008.

ODA, Teruko. Furusato no Uta: Canção da Terra. São Paulo: Escrituras, 2010. 